\title{
Prospective client survey and participatory process ahead of opening a mobile drug consumption room in Lisbon
}

Hannah Taylor ${ }^{*}$ (D), Adriana Curado², Joana Tavares ${ }^{3}$, Miguel Oliveira² $^{2}$, Diana Gautier ${ }^{3}$ and João Santa Maria ${ }^{2}$

\begin{abstract}
Background: Ahead of opening Portugal's first mobile drug consumption room (MDCR) in Lisbon, information from People Who Use Drugs (PWUD) and local community members was necessary to determine current needs and shape the intervention. A participatory and peer-led process was ensured at all stages of data gathering and planning of the intervention.
\end{abstract}

Methods: Prospective clients were surveyed to determine their willingness to use the service and preferences for use and to gain sociodemographic information. Persons over the age of 18 who reported injection drug use (PWID) were recruited using convenience sampling in the main open drug use scenes in Lisbon. In-person interviews were conducted by trained peer workers between November and December of 2017. The results $(n=72)$ of the questionnaires were analyzed, providing descriptive statistics.

Results: There is a high level of willingness to use the MDCR, primarily for reasons of hygiene, privacy, and security. Most participants expressed a desire to use the MDCR daily. Potential clients are socially marginalized, and many suffer from unstable housing. Most are daily users and engage in unsafe injecting practices, such as public injecting and material sharing. High levels of hepatitis C, HIV, and hepatitis B were observed among the target population with low levels of healthcare access and utilization. Preferences were gauged regarding the scheduling of the MDCR's hours and amount of time willing to travel to reach the MDCR and will be taken into account for implementation. The combination of high levels of willingness to utilize the service and high levels of need among the target population support the implementation of Lisbon's first MDCR.

Conclusions: Continual participation of PWUD and other community members will be necessary to maximize the public health and social impacts of this intervention, relative to this baseline. The plan to continue the participatory and peer-led development of the MDCR includes integrating peer workers, clients, and local community members within the operation, management, and evaluation of the service. This research adds to a growing literature about drug consumption rooms (DCRs) in Europe, which is especially limited concerning MDCRs.

Keywords: Drug consumption rooms, Mobile drug consumption room, Prospective client survey, People who inject drugs, Harm reduction, Portugal

\footnotetext{
* Correspondence: hct245@nyu.edu

'Universidade Nova de Lisboa Faculdade de Ciencias Sociais e Humanas,

Lisbon, Portugal

Full list of author information is available at the end of the article
}

(c) The Author(s). 2019 Open Access This article is distributed under the terms of the Creative Commons Attribution 4.0 International License (http://creativecommons.org/licenses/by/4.0/), which permits unrestricted use, distribution, and reproduction in any medium, provided you give appropriate credit to the original author(s) and the source, provide a link to the Creative Commons license, and indicate if changes were made. The Creative Commons Public Domain Dedication waiver (http://creativecommons.org/publicdomain/zero/1.0/) applies to the data made available in this article, unless otherwise stated. 


\section{Background}

Drug consumption rooms (DCRs) are both public health and social interventions and aim to prevent disease transmission and overdose-related deaths $[4,18]$ as well as to mitigate the negative community-level effects of public drug use [1]. In addition to providing direct services, DCRs offer education on safer injecting practices [23]. Users tend to adopt these safer practices even outside of the facility [6]. Furthermore, DCRs act as key sites for a referral to further services $[13,23]$ for people who use drugs (PWUD).

DCRs attract the most socially marginalized [23] and atrisk users in terms of health $[12,17,23]$, and therefore represent harm reduction mechanisms with a great potential for impact. Users of DCRs are more likely to be in unstable housing situations [21], have recently overdosed [21], and be at elevated risk of bloodborne diseases from unsafe injection or syringe-sharing practices [21].

Positive health outcomes of DCR utilization include fewer overdoses and overdose deaths [12]. In addition, the interplay between behavioral changes and health outcomes include less rushed injecting [17], syringe sharing [23], and HIV risk behavior [12]. Positive effects for the surrounding community expand to less public injecting, less unsafe syringe disposal [17, 18], and less public disorder [23]. While most studies did not find increased drug dealing, trafficking, or crime in the areas surrounding the DCR $[12,18$, 23], limited evidence has demonstrated increased aggressive incidents in the vicinity of the site, petty crime increases, and resentment on the part of local residents [12].

DCRs have been legally possible in Portugal for almost two decades but have not before been implemented. The overhaul of Portugal's drug policy is summarized in the 1999 National Drug Strategy, which lays out a shift toward a less repressive drug policy and one centered on humanism, pragmatism, and public health. In 2001, both the decriminalization of low-level possession and use of illicit drugs and the Decree-law 183, regulating harm reduction responses, came into effect. DCRs are among the harm reduction measures detailed. However, the relevant law restricts DCR locations to areas that are not densely populated. The opening of a MDCR, which is part of a larger initiative by the city government and harm reduction NGOs to open 3 DCRs, two fixed and one mobile, allows service of the densely populated urban center. Only injection consumption is possible in the van due to limited space and lack of smoke extraction capacities.

DCRs are developed with their target population in consideration and therefore customized to the local drug-using population [1]. In order to maximize the benefits for users of DCRs, feasibility studies are utilized to understand the demand for DCRs [1, 2, 7, 10, 14] and characteristics of users ahead of opening DCRs [11] and call on both PWUD and other local experts.
Generally, the level of willingness to utilize a consumption site is high $[1,11]$. Prospective surveys also assess the concerns of the PWUD population concerning the consumption site $[1,11]$, such as deterrents for use. Furthermore, they provide information on the anticipated frequency of use and desired scheduling [14] and location [10]. Finally, these surveys help the implementers of the DCRs ensure that they will reach the most vulnerable population $[2,7,10,11,14]$. Together, this information allows those in charge of implementing the site to maximize its reach and efficacy.

Once the service is implemented, there is a need for continual evaluation of the service's efficacy and user satisfaction $[16,17]$. In addition to the constraints that DCRs face, such as operating hours and waiting times [17], there are additional challenges of capacity, weather conditions, and other location-specific limitations unique to MCDRs [16].

The implementation of a pilot MDCR is a collaboration between Grupo de Ativistas em Tratamentos (GAT), Médicos do Mundo, and the City Council of Lisbon. Activities carried out through September of 2017 to January 2018 were divided into three main categories: diagnostic, training for teams and partners, and preparation of a final report. The diagnostic process included defining the methodology and data collection instruments for the site, field work including identification and characterization of intervention areas and conceptualization of consumption spaces, local partner meetings, and a prospective client survey. This survey of prospective clients provided data on socioeconomic characteristics, consumption patterns, health status, and both acceptability of and preferences for a MDCR in Lisbon.

Within the field of harm reduction, there is an evergrowing commitment to integrate peers in all aspects of research and intervention $[8,15,20]$. Peers offer unique skills and knowledge in the harm reduction field because of their lived experiences [15]. One broad definition of peers is that they are "any persons with equal standing within a particular community who share a common lived experience" [20]. For the purpose of this study, peers are persons who have used or currently use drugs. Additionally, they comprise a subset of PWUD because they are PWUD who are contributing to the harm reduction intervention in question. Peer workers are peers who are trained to administer harm reduction services and are paid staff members.

In the planning of this intervention, care has been taken to ensure the participation of peers. Peer workers administered the survey to users and interfaced with community members during the fieldwork period. Additionally, Consumidores Associados Sobrevivem Organizados (CASO), the only association of people who use drugs in Portugal, has participated since the beginning of the discussion concerning DCRs in Lisbon. The recommendations made by 
CASO for the implementation of DCRs can be found in the Appendix. The plan to continue a participatory and peer-led process for the DCR extends to the operation, management, and evaluation of the service. The results of the prospective client survey and how they, alongside a peer-led planning process, guide the intervention's implementation are the primary focus of the present paper.

\section{Methods}

A survey of prospective clients of the MDCR was carried out to learn about the target population, their needs, and their preferences for a potential mobile unit. The design of the survey was influenced both by literature reviews and the advice of peers, specifically peer workers who are GAT staff and from members of CASO who are not GAT staff. The survey was divided into three main sections: sociodemographic characteristics, patterns of consumption and use behaviors, and acceptability and willingness to use a MDCR in Lisbon.

Questionnaires were administered by trained peer workers between November 10 and December 18, 2017, during the outreach period in the communities identified as potential intervention sites. Persons over the age of 18 who reported current injection drug use were eligible to participate, as they comprise the target population of the intervention. Those reporting other types of consumption, namely smoking, were excluded from participating. There were no monetary incentives offered for participation. Informed consent was collected from all participants, including an agreement that their responses may be included in scientific publications. No additional ethical review was sought for this study. Interviews were conducted in Portuguese. Given the small sample size $(n=72)$, analysis of the results was limited to descriptive statistics.

\section{Results}

\section{Sociodemographic characteristics of participants}

Participants in the study were mostly men (81\%), Portuguese $(75 \%)$, and over 40 years old (69\%), with a mean age of 43.53 years. Most of the participants born outside of Portugal come from African Portuguese Speaking Countries (72\%). Forty percent of the participants were in unstable, versus stable, housing situations corresponding to the ETHOS [5] definition of homelessness at the time of survey administration. Among these, most (72\%) sleep on the street or in a temporary shelter. See Table 6 in the Appendix for percentages of respondents by type of insecure housing (Table 1).

\section{Consumption patterns and associated behaviors}

The vast majority of participants reported injected consumption of crack cocaine (79\%) and heroin $(75 \%)$ in the last 6 months. Other substances injected were powder cocaine (43\%), benzodiazepines (15\%), buprenorphine $(6 \%)$, and methadone (3\%).

Most participants are daily (57\%) or regular users (25\%), reporting at least one weekly consumption. Of those surveyed, $14 \%$ used syringes and/or needles they knew or suspected had been used by another person in the last 6 months, and 24\% reported having shared other injection material such as spoons/cups, filters, water, or alcohol pads in the last 6 months. Regarding the site of consumption, $61 \%$ of respondents reported a public space (Table 2).

When asked about opioid overdoses in the past 12 months, $8 \%$ of users (six users) reported having at least one overdose. Eighty-eight percent of all participants $(n=58)$ reported currently being in an opioid substitution program.

To better understand the current health statuses of participants, questions were asked regarding the most frequently transmitted infections among PWID (HIV, hepatitis B, and hepatitis $\mathrm{C}$ ) and associated complications, such as vein damage and bacterial infections. Regarding HIV infection, $14 \%$ of the respondents reported positive serological status, of which $60 \%$ indicated that they were not on treatment (Table 3 ).

Regarding hepatitis C Virus (HCV) infection, $43 \%$ reported positive serological status, of which only $3 \%$ indicated being in treatment, $23 \%$ on hospital follow-up, and the majority (74\%) answered not being treated, nor on follow-up. Of the participants who reported negative serological status, $23 \%$ reported that they either were spontaneously cured or successfully treated. Hepatitis B virus (HBV) infection was less prevalent.

As for other complications associated with injected consumption, especially related to lack of hygiene and bad injection practices, $29 \%$ of the participants reported

Table 1 Sociodemographic characteristics of participants ( $n=$ 72)

\begin{tabular}{lll}
\hline & Number & Percent \\
\hline Gender & 58 & 81 \\
Male & 13 & 18 \\
Female & 1 & 1 \\
Transgender & & \\
Age group & 22 & 31 \\
$\quad<40$ years & 50 & 69 \\
$>40$ years & & \\
Country of birth & 54 & 75 \\
Portugal & 18 & 25 \\
Other & & \\
Housing situation & 29 & 40 \\
Unstable & 43 & 60 \\
Stable & & \\
\hline
\end{tabular}


Table 2 Drug use patterns in the past 6 months $(n=72)$

\begin{tabular}{|c|c|c|}
\hline & Number & Percent \\
\hline \multicolumn{3}{|l|}{ Frequency of injection drug use } \\
\hline Every day & 41 & 57 \\
\hline From time to time, not every week & 13 & 18 \\
\hline Once or twice a week & 8 & 11 \\
\hline Three to five times per week & 10 & 14 \\
\hline \multicolumn{3}{|l|}{ Substances injected } \\
\hline Crack cocaine & 57 & 79 \\
\hline Heroin & 54 & 75 \\
\hline Cocaine powder & 31 & 43 \\
\hline Benzodiazepine & 11 & 15 \\
\hline Buprenorphine & 4 & 6 \\
\hline Methadone & 2 & 3 \\
\hline Other & 1 & 1 \\
\hline \multicolumn{3}{|l|}{ Sites used for consumption } \\
\hline On the street & 32 & 44 \\
\hline In own home or friend's home & 30 & 42 \\
\hline Open fields & 19 & 26 \\
\hline In public bathrooms & 13 & 18 \\
\hline In the car & 9 & 13 \\
\hline In abandoned buildings & 6 & 8 \\
\hline In occupied homes & 4 & 6 \\
\hline In improvised, user-managed rooms & 3 & 4 \\
\hline Other locations & 2 & 3 \\
\hline In temporary lodges & 1 & 1 \\
\hline
\end{tabular}

Table 3 Self-reported serostatus $(n=72)$

\begin{tabular}{lll}
\hline & Number & Percent \\
\hline HIV serostatus & 56 & 78 \\
Negative & 10 & 14 \\
Positive & 5 & 7 \\
Do not know & 1 & 1 \\
Did not respond & & \\
HCV serostatus & 35 & 49 \\
Negative & 31 & 43 \\
Positive & 5 & 7 \\
Do not know & 1 & 1 \\
Did not respond & & \\
HBV serostatus & 47 & 56 \\
Negative & 4 & 6 \\
Positive & 20 & 1 \\
Do not know & 1 & \\
Did not respond & &
\end{tabular}

a bacterial infection in the last 6 months and 32\% reported some type of vein damage in the last 6 months.

\section{Acceptability and willingness to use a mobile drug consumption unit in Lisbon}

The final section of the survey was intended to access users' acceptability and willingness to use a MDCR. Eighty-nine percent indicated that they were willing to use such a service. Among the $7 \%$ of participants who reported being unwilling to use the MDCR, the primary reason was already having a space to consume. Of those willing, all cited that they would use it due to hygiene reasons $(100 \%)$, and the vast majority $(89 \%)$ stated that they would do so for reasons of privacy and security (Table 4).

For those who indicated willingness to use the MDCR, information was collected on how often they wish to use the service, their preferences regarding operating times, and how much time they were willing to travel to reach a mobile unit. The majority (75\%) indicated a willingness to use the mobile unit every day. For time willing to travel, $27 \%$ reported being willing to travel between 21 and 30 min, while the majority of participants reported being willing to travel for a lesser amount of time (Table 5).

\section{Discussion}

With high levels of desire to participate and potential clients presenting high levels of health and social risk, Lisbon's first MDCR holds the potential to improve the health, safety, and quality of life of PWID and communities affected by consumption in public spaces. Current harm reduction services available in Lisbon include mobile methadone units, street teams which provide material exchanges, treatment centers, rapid testing, and referrals within this network and to other health and social services. None of these services provides a safe space for users in a moment of heightened risk: that of consumption. Therefore, this initiative represents a complementary service to what already exists. The relatively small (23\%) percentage of people seeking referrals does not necessarily indicate that users only need a safe place to consume, but rather that there is a strong network of harm reduction services available in Lisbon and that they are already accessing them, but that this service is still missing. Anticipated positive outcomes include access to safer injecting conditions, reducing morbidity and mortality associated with overdose and the harms associated with injecting, service access and referral of PWIDs to existing networks of health and social services Lisbon, and increased public awareness and acceptance concerning the benefits of DCRs. Expected positive community-level impacts include less public syringe disposal and less public injecting $[17,18]$.

MDCRs represent a newer addition to the harm reduction sphere in terms of injection facilities, with benefits being their flexibility to change location in accordance 
Table 4 Utilization potential for a MDCR in Lisbon

\begin{tabular}{|c|c|c|}
\hline & Number & Percent \\
\hline \multicolumn{3}{|l|}{ Willingness to use } \\
\hline Yes & 64 & 89 \\
\hline No & 5 & 7 \\
\hline Do not know & 3 & 4 \\
\hline \multicolumn{3}{|l|}{ Reasons for using a MDCR } \\
\hline $\begin{array}{l}\text { Security: fear of overdose, to avoid material } \\
\text { sharing, avoiding street, or police violence }\end{array}$ & 57 & 89 \\
\hline $\begin{array}{l}\text { Privacy: to avoid having to consume in public } \\
\text { spaces }\end{array}$ & 57 & 89 \\
\hline $\begin{array}{l}\text { Hygiene: to have access to a clean space for } \\
\text { consumption and necessary equipment }\end{array}$ & 64 & 100 \\
\hline Support from a specialized team & 50 & 78 \\
\hline $\begin{array}{l}\text { Access to other services such as nurses, } \\
\text { screening, referrals, peer counseling }\end{array}$ & 15 & 23 \\
\hline Other reasons & 1 & 2 \\
\hline \multicolumn{3}{|l|}{ Reasons not to use a MDCR } \\
\hline Already have a space to consume & 4 & 80 \\
\hline $\begin{array}{l}\text { Privacy: afraid of confidentiality breaches by } \\
\text { the team, do not wish to be seen entering } \\
\text { the space, do not wish to be seen by other } \\
\text { clients }\end{array}$ & 0 & 0 \\
\hline Prefer to consume alone & 1 & 20 \\
\hline Worried about other clients' behavior & 1 & 20 \\
\hline Ashamed to consume in front of a technician & 2 & 40 \\
\hline \multicolumn{3}{|l|}{ Frequency of use of the MDCR } \\
\hline Every day & 48 & 75 \\
\hline Several times per week & 5 & 8 \\
\hline At least once per month & 3 & 5 \\
\hline Once or twice & 0 & 0 \\
\hline Do not know & 8 & 13 \\
\hline
\end{tabular}

with the needs of their target population and to respond to drug market shifts or pressures from other sources such as law enforcement [3]. This represents a shift toward safer environment interventions [19] rather than pushing for social or behavioral change on the part of users. For MDCRs to successfully serve the populations that they operate within, it is necessary to have supportive local environments both in terms of local government and law enforcement and the community members surrounding the service [3]. Though mobile units tend to have lower capacity than fixed locations, they can be complementary to the services offered at fixed locations or open up doors for their implementation [3].

The team responsible for implementation is committed to an integrated and participatory approach to the health and social needs of PWID in Lisbon. All intervention is guided by the principles of public health, human rights, and evidence-based practices. In addition to
Table 5 Preferences for MDCR operation

\begin{tabular}{lll}
\hline & Number & Percent \\
\hline Preferred operation hours for a MDCR & & 22 \\
Mornings (8 a.m.-12 p.m.) & 14 & 2 \\
Afternoon (12 p.m.-4 p.m.) & 1 & 27 \\
Evening (4 p.m.-8 p.m.) & 17 & 20 \\
Night (8 p.m.-12 a.m.) & 13 & 28 \\
Any time & 18 & 2 \\
Do not know & 1 & \\
Time willing to travel to reach a MDCR & & 8 \\
1-5 min & 5 & 25 \\
6-10 min & 16 & 28 \\
11-20 min & 18 & 27 \\
21-30 min & 17 & 11 \\
Do not know & 7 & 2 \\
No information & 1 & \\
\hline
\end{tabular}

integrating peers in the planning and evaluation processes, participation extends to professionals working in the area and local and strategic partners. In accordance with this, proposals for locations of the MDCR stops come from the insights of the neighborhood teams and local partners and prioritize access to users, privacy, and the needs of the local community. As the service operates, consistent communication with clients will be fostered in order to adapt to their needs and opinions.

Furthermore, in order to ensure that the service provision is in line with the needs of the target population and to give PWUD a voice in the program's management, trained peer workers will be a part of the staff. Peers will also work in the proximity of the mobile unit to provide information, mediate conflicts, collect materials, and invite PWUD to engage with the initiative. This will minimize any negative impacts of the intervention on the public space and help foster a climate of acceptance.

Table 6 Characterization of precarious housing

\begin{tabular}{lll}
\hline & Number & Percent \\
\hline $\begin{array}{l}\text { No roof: sleeping in the street or overnight shelter } \\
\text { or temporary shelter for less than } 3 \text { months, forced }\end{array}$ & 21 & 72 \\
to spend several hours a day in a public space. & & \\
$\begin{array}{l}\text { Homeless: living in a shelter, refugee centers, prison, } \\
\text { community therapy, a psychiatric hospital. }\end{array}$ & 10 \\
$\begin{array}{l}\text { Unsafe housing: living temporarily with family or } \\
\text { friends (not by choice), not having a lease (excluding }\end{array}$ & 2 & 7 \\
$\begin{array}{l}\text { squatting), subject to threat of eviction, living under } \\
\text { threat of partner or family violence. }\end{array}$ & \\
$\begin{array}{l}\text { Inadequate housing: living in a mobile home, } \\
\text { caravan, van, squatting, living in overcrowded }\end{array}$ & 3 & 10 \\
housing. & & \\
Total & 29 & 100 \\
\hline
\end{tabular}


Though DCRs operate in diverse settings, much of the English-language literature originates from isolated cases. Notably, the Insite center in Vancouver has been well-studied [6, 11, 21-23], as has a DCR in Sydney $[13,17]$. In Europe [12], where the majority of DCRs operate, much of the literature is not in English [1,9]. This paper also adds field knowledge concerning a specific and less-well-documented form of consumption space, a MDCR. Furthermore, the insights gained from the involvement of peers in all aspects of the implementation, from advising, to research, to publication and evaluation of the service, represent an important addition to the literature.

Limitations of the current study include a small sample size, which limits the statistical power and generalizability of the findings to the larger population of PWID in Portugal. However, this research provides a baseline of the characteristics, behaviors, and attitudes of potential clients. Future analyses of those who utilize the service will be more robust in terms of sample size. This paper is intended to be the first in a series which continually evaluate this intervention for its target population and the larger community. Analysis of the impact of this intervention will not be limited to the experiences of clients but will also account for the response in terms of public health and social impact in the surrounding communities.

\section{Conclusions}

Diagnostic information shows that PWID are an aging population, mostly over 40 years of age, and suffering from poverty and social exclusion, especially as it relates to housing. The intervention will target PWID with greater vulnerability who are consuming publicly or in other risk conditions. Most are regular or daily users of crack cocaine and heroin. The percentage who report sharing material is still significant enough to cause concern and likely is related to the public conditions in which they consume. Health-wise, the population has high levels of hepatitis $C$, HIV, and hepatitis B prevalence with low levels of treatment of these infections. Sixty percent of people living with HIV are not in treatment and $74 \%$ with hepatitis C are not receiving specialized care. The data highlights a prevalence of other complications associated with injected consumption, which, when untreated, can result in serious or even irreversible damages.

Given the overwhelming willingness to use the MDCR, it is expected that there will be an improvement in health outcomes among the target population of this service. Even PWID who do not utilize the service may benefit indirectly from a reduction in drug-related infections among their peers. Involvement of local and strategic partners will continue to be prioritized given the innovative and experimental nature of the proposed intervention as an addition to Portugal's harm reduction landscape. Above all, peer input is considered necessary to arrive at a service that is in and of the community it serves.

\section{Appendix}

Recommendations made by CASO for the implementation of the assisted consumption rooms:

1. Involvement of civil society is very important, especially of those affected, who possess unique experiential knowledge, easy access to the places where drugs are consumed, and privileged relationships of trust. With proper motivation and training, they can develop methods of proven effectiveness and efficiency, and at the same time that direct investment is channeled to the people who need it the most. We are promoting health literacy and rights, therefore, to enable active citizenship.

2. Adopt a model that is truly person-centered and pragmatic and therefore not hospital-based nor centered on disease and treatment.

3. Promote a model of governance that is as horizontal and participatory as possible (involving the local community, drug users, security forces, etc.).

4. The law restricting use within DCRs to injection should be updated.

5. Fixed-location DCRs should present a broad set of responses to the needs of those who use them (legal, medical, psychosocial and peer support, but also distribution of consumption material, clothing, personal hygiene, lockers, among others).

6. Mobile units should develop actions not only directed toward the interior of the van but should rather use the van as a focal point for interventions by teams that include peer educators, mediators, and consultants.

\section{Abbreviations}

DCR: Drug consumption room; MDCR: Mobile drug consumption unit; PWID: People who inject drugs; PWUD: People who use drugs

\section{Acknowledgements \\ The authors would like to thank the City Council of Lisbon for their support and funding of the work done in preparation to open Portugal's first pilot mobile drug consumption room. Furthermore, the authors extend their gratitude to Ares do Pinhal, Crescer, DICAD, and SICAD for their partnership in this process. We would also like to thank the GAT's IN-Mouraria harm re- duction team and Médicos do Mundo's Saúde a Girar team for sharing their knowledge and experience throughout the course of this research. Finally, we thank all research participants for their valuable contribution.}

\section{Authors' contributions}

$A C, M O, J T$, and JM designed the study and developed the questionnaire. $\mathrm{MO}$ undertook the data collection. AC and HT analyzed the data. HT and AC prepared the first draft of the article. $H T, A C, J T$, and DG edited the revised manuscript. All authors contributed to the revision of the manuscript. All authors read and approved the final manuscript. 
Authors' information

Not applicable.

\section{Funding}

Funding to conduct this study was provided by the City Council of Lisbon.

\section{Availability of data and materials}

The survey questionnaire and informed consent forms used in this article are available upon request. The dataset analyzed during the current study is not available. Participants were assured during the informed consent process that individual responses were confidential.

\section{Ethics approval and consent to participate}

Participants were informed of the aims of the study and that their responses may be included in scientific publications. No ethical approval was sought for this research.

\section{Consent for publication}

Not applicable.

\section{Competing interests}

The authors declare that they have no competing interests.

\section{Author details}

'Universidade Nova de Lisboa Faculdade de Ciencias Sociais e Humanas, Lisbon, Portugal. ${ }^{2}$ GAT - Grupo de Ativistas em Tratamentos, Lisbon, Portugal. ${ }^{3}$ Médicos do Mundo, Lisbon, Portugal.

Received: 1 April 2019 Accepted: 30 July 2019

Published online: 09 August 2019

\section{References}

1. Atkin-Brenninkmeyer E, Larkan F, Comiskey C. Factors concerning access to a potential drug consumption room in Dublin, Ireland. Cogent Social Sciences. 2017;3(1):1398207.

2. Broadhead RS, Borch CA, Van Hulst Y, Farrell J, Villemez WJ, Altice FL. Safer injection sites in New York City: A utilization survey of injection drug users. J Drug Iss. 2003;33(3):733-50.

3. Dietze P, Winter R, Pedrana A, Leicht A, Majo I Roca X, Brugal MT. Mobile safe injecting facilities in Barcelona and Berlin. Int J Drug Policy. 2012 Jul; 23(4):257-60.

4. European Monitoring Centre for Drugs and Drug Addiction. Drug consumption rooms: an overview of provision and evidence. 2018. Available online: http://www.emcdda.europa.eu/system/files/publications/2734/POD_ Drug\%20consumption\%20rooms.pdf. Accessed 12 Nov 2017.

5. FEANTSA. ETHOS-European typology on homelessness and housing exclusion. 2005

6. Fast D, Small W, Wood E, Kerr T. The perspectives of injection drug users regarding safer injecting education delivered through a supervised injecting facility. Harm Reduct J. 2008;5(1):32.

7. Green TC, Hankins CA, Palmer D, Boivin J, Platt R. My place, your place, or a safer place: the intention among Montreal injecting drug users to use supervised injecting facilities. Can J Public Health. 2004:110-4.

8. Greer AM, Luchenski SA, Amlani AA, Lacroix K, Burmeister C, Buxton JA. Peer engagement in harm reduction strategies and services: a critical case study and evaluation framework from British Columbia, Canada. BMC Public Health. 2016;16(1):452.

9. Hedrich D, Kerr T, Dubois-Arber F. Drug consumption facilities in Europe and beyond. European Monitoring Centre for Drugs and Drug Addiction (EMCDDA), Harm reduction: evidence, impacts and challenges, Rhodes, T. and Hedrich, D.(eds), Scientific Monograph Series 2010;10.

10. Hunt N, Lloyd C, Kimber J, Tompkins C. Public injecting and willingness to use a drug consumption room among needle exchange programme attendees in the UK. Int J Drug Policy. 2007;18(1):62-5.

11. Kerr T, Wood E, Small D, Palepu A, Tyndall MW. Potential use of safer injecting facilities among injection drug users in Vancouver's Downtown Eastside. CMAJ. 2003;169(8):759-63.

12. Kimber J, Dolan K, Wodak A. Survey of drug consumption rooms: service delivery and perceived public health and amenity impact. Drug Alcohol Rev. 2005;24(1):21-4.
13. Kimber J, Mattick RP, Kaldor J, van Bleek I, Gilmour S, Rance JA. Process and predictors of drug treatment referral and referral uptake at the Sydney Medically Supervised Injecting Centre. Drug Alcohol Rev. 2008;27(6):602-12.

14. Kral AH, Wenger L, Carpenter L, Wood E, Kerr T, Bourgois P. Acceptability of a safer injection facility among injection drug users in San Francisco. Drug Alcohol Depend. 2010;110(1-2):160-3.

15. Marshall Z, Dechman M, Minichiello A, Alcock L, Harris GE. Peering into the literature: a systematic review of the roles of people who inject drugs in harm reduction initiatives. Drug Alcohol Depend. 2015;151:1-14.

16. Mema SC, Frosst G, Bridgeman J, Drake H, Dolman C, Lappalainen L, et al. Mobile supervised consumption services in Rural British Columbia: lessons learned. Harm Reduct J. 2019;16(1):4.

17. Petrar S, Kerr T, Tyndall MW, Zhang R, Montaner JS, Wood E. Injection drug users' perceptions regarding use of a medically supervised safer injecting facility. Addict Behav. 2007;32(5):1088-93.

18. Potier C, Laprévote V, Dubois-Arber F, Cottencin O, Rolland B. Supervised injection services: what has been demonstrated? A systematic literature review. Drug Alcohol Depend. 2014;145:48-68.

19. Rhodes T, Kimber J, Small W, Fitzgerald J, Kerr T, Hickman M, et al. Public injecting and the need for 'safer environment interventions' in the reduction of drug-related harm. Addiction. 2006;101(10):1384-93.

20. Ti L, Tzemis D, Buxton JA. Engaging people who use drugs in policy and program development: a review of the literature. Subst Abuse Treat Prev Policy. 2012;7(1):47.

21. Wood E, Tyndall MW, Li K, Lloyd-Smith E, Small W, Montaner JS, et al. Do supervised injecting facilities attract higher-risk injection drug users? Am J Prev Med. 2005;29(2):126-30

22. Wood E, Kerr T, Small W, Li K, Marsh DC, Montaner JS, et al. Changes in public order after the opening of a medically supervised safer injecting facility for illicit injection drug users. CMAJ. 2004;171(7):731-4.

23. Wood E, Tyndall MW, Montaner JS, Kerr T. Summary of findings from the evaluation of a pilot medically supervised safer injecting facility. CMAJ. 2006; 175(11):1399-404.

\section{Publisher's Note}

Springer Nature remains neutral with regard to jurisdictional claims in published maps and institutional affiliations.

\section{Ready to submit your research? Choose BMC and benefit from:}

- fast, convenient online submission

- thorough peer review by experienced researchers in your field

- rapid publication on acceptance

- support for research data, including large and complex data types

- gold Open Access which fosters wider collaboration and increased citations

- maximum visibility for your research: over $100 \mathrm{M}$ website views per year

At BMC, research is always in progress.

Learn more biomedcentral.com/submissions 